\title{
PROPOSTA DE REVITALIZAÇÃO PAISAGÍSTICA DE CAVAS DA BACIA DO RIO IGUAÇU NA REGIÃO METROPOLITANA DE CURITIBA
}

\author{
LANDSCAPE REVITALIZATION PROPOSAL OF SAND HOLES OF IGUASSU RIVER BASIN \\ AT CURITIBA'S METROPOLITAN REGION
}

\begin{abstract}
Livia Yu Iwamura
Arquiteta e urbanista pela Universidade Federal do Paraná (UFPR), mestranda em Engenharia Civil pela Universidade Tecnológica Federal do Paraná (UTFPR) e arquiteta e urbanista da Universidade Federal da Integração Latino-Americana (UNILA)

livia.iwamura@gmail.com
\end{abstract}

\section{Júlio César Rodrigues de Azevedo}

Químico pela Pontifícia Universidade Católica do Paraná (PUC-PR), mestre em Química pela Universidade Estadual de Maringá (UEM), doutor em Ecologia de Ambientes Aquáticos Continentais pela (UEM) e professor da UTFPR

jcrazevedo@utfpr.edu.br

\section{Célia Regina Gapski Yamamoto}

Arquiteta e urbanista pela UFPR, mestre em Planejamento Ambiental pela Kobe University, arquiteta e urbanista do Instituto das Águas do Paraná e professora do Instituto Federal do Paraná (IFPR)

celiagyamamoto@gmail.com

\section{RESUMO}

A presente pesquisa teve como objetivo analisar a situação atual e definir diretrizes de projeto para a revitalização de um conjunto de cavas de areia situadas na bacia do rio lguaçu da região metropolitana de Curitiba (RMC). A localização em área de manancial da RMC implicou na análise de fatores restritivos ambientais. Outro viés abordado foi o diagnóstico da RMC a partir de aspectos socioeconômicos, em especial no que diz respeito ao processo de ocupação irregular. No que concerne ao diagnóstico específico da área de estudo, a caracterização da água armazenada nas cavas é crucial para a definição de diretrizes de revitalização. A proposta se baseou na avaliação limnológica de nove coletas realizadas no período de abril de 2008 a novembro de 2009. A análise considerou os parâmetros estabelecidos pela Resolução n. 357/2005 do Conselho Nacional de Meio Ambiente. $O$ cruzamento dessas informações resultou em uma proposta organizada em seis setores principais: extração mineral controlada, amortecimento, recreação pública, pesquisa e educação ambiental, recuperação da mata ciliar, wetlands construídas.

Palavras-chave: Cavas de areia, paisagem, recursos hídricos, região metropolitana de Curitiba, rio Iguaçu.

\section{ABSTRACT}

The purpose of this research was to analyze the current situation and define design guidelines for the landscape revitalization of sand holes located at lguassu River Basin in Curitiba's Metropolitan Region (RMC). The location at a water source area involved the analysis of restrictive environmental factors. Another issue was the RMC diagnosis from socioeconomic aspects, particularly about the process of illegal occupation. The revitalization proposal of the studied area is directly related to the characterization of water stored in 
the sand holes, which was based on limnological assessment of nine samples collected from April 2008 to November 2009. The analysis used parameters defined by the 357/2005 Resolution of Environmental National Council. The result was a proposal organized into six main sectors: controlled mining; damping; public recreation; environmental research and education; riparian vegetation recovery; constructed wetlands.

Keywords: Sand holes, landscape, hidric resources, curitiba's metropolitan region, iguassu river.

\section{INTRODUÇÃO}

No Brasil, a privilegiada disponibilidade hídrica serviu de suporte à cultura do desperdício, à pequena valorização econômica e ao adiamento dos investimentos necessários a seu uso e proteção.

O êxodo rural, a industrialização e o crescimento urbano desordenado são fenômenos diretamente relacionados à água, pois induzem à concentração da demanda e alterações da caracterização hídrica. No Brasil, esse processo iniciou na década de 1950 e intensificou-se desde então (SETTI et al, 2000). Por outro lado, Andreoli et al (1999) destacam que a disponibilidade, caracterização e quantidade de água são fatores limitantes ao desenvolvimento das cidades. $\bigcirc$ uso sustentável desse recurso pressupõe a existência de instrumentos de proteção, planejamento e utilização adequados. A manutenção dos parâmetros de potabilidade da água é crucial, sobretudo, nas bacias de abastecimento.

No caso da região metropolitana de Curitiba (RMC), há uma peculiaridade: o início da ocupação ocorreu nas cabeceiras do rio lguaçu, levando à urbanização de uma importante área de manancial. $\bigcirc$ desenvolvimento de Curitiba tem incentivado o crescimento da região metropolitana, que, muitas vezes, manifesta-se na forma de invasões. As agressões ao meio ambiente, além de comprometerem a natureza, afetam a qualidade de vida da população (FABIANOVICZ, 1998).

Fabianovicz (1998) destaca também que, desde a década de 1940, ocorre a extração de argila e areia nas várzeas do rio Iguaçu. A atividade é extremamente agressiva: além de destruir a biota, deixa uma cicatriz no relevo. A cava abandonada passa a acumular água; a mata ciliar é suprimida e substituída pela vegetação lacustre.

Segundo a SUDERHSA (2007), a sub-bacia do Alto Iguaçu abriga a maioria dos mananciais de abastecimento de água em uso pela RMC. Em 2006, uma grave estiagem afetou a RMC, levando a Companhia de Saneamento do Paraná (SANEPAR) a utilizar a água acumulada nas cavas do rio Iguaçu, especificamente da área compreendida entre a avenida Iraí e a BR 277. Conforme informações da SANEPAR, foi outorgada uma vazão de bombeamento de 590L/s para os meses de julho e agosto de 2006. Segundo Pereira (2007), o uso das cavas como manancial foi viabilizado pelo não comprometimento do ecossistema existente.

A disponibilidade de água para abastecimento também está relacionada à polvição hídrica. Infelizmente, o atual estado de degradação dos rios Palmital e Atuba levaram a Coordenação da região metropolitana de Curitiba (COMEC) a cogitar o abandono do rio Iguaçu como manancial. Avaliações da caracterização hídrica da sub-bacia do 
Alto Iguaçu têm apresentado índices abaixo das recomendações do Conselho Nacional de Meio Ambiente (Conama), na maior parte dos cursos de água (SUDERHSA, 2007). Tal situação requer medidas urgentes de requalificação dos corpos hídricos, uma vez que o crescimento expressivo da população da RMC não pode tolerar negligências no abastecimento público. A melhoria da qualidade da água dos mananciais pode ocorrer por meio de soluções alternativas como wetlands construídas, cuja implantação é favorecida em áreas de várzea.

Este trabalho tem como objetivo traçar um diagnóstico da situação atual e estudar uma proposta de recuperação, conservação e melhoria de um conjunto de cavas de areia da bacia do rio Iguaçu na região metropolitana de Curitiba. A proposta visa conciliar áreas de lazer, educação ambiental, pesquisa, tratamento de águas residuárias e extração mineral controlada em um mesmo espaço, ampliando serviços à população e diminuindo a demanda por equipamentos urbanos.

\section{DIAGNÓSTICO DA RMC}

Em 1973, a Lei Federal Complementar n. 14 estabeleceu oito regiões metropolitanas, dentre as quais a região metropolitana de Curitiba (RMC). Originalmente, a RMC era composta por 14 municípios; atualmente há 26 municípios, considerando como última inclusão a Lapa em 2002.

A Tabela 1 expõe dados do Paraná, RMC e municípios onde se situa a área de estudo (Piraquara e São José dos Pinhais), bem como municípios limítrofes à área (Curitiba e Pinhais):

Tabela 1: Dados gerais do Paraná, RMC, Curitiba, Pinhais, Piraquara e São José dos Pinhais

\begin{tabular}{lcccccc}
\hline & Paraná & RMC & Curitiba & Pinhais & Piraquara & $\begin{array}{c}\text { São José } \\
\text { Pinhais }\end{array}$ \\
\hline Data de criação & $19 / 12 / 1853$ & $08 / 06 / 1973$ & $29 / 03 / 1693$ & $18 / 03 / 1992$ & $17 / 01 / 1890$ & $27 / 12 / 1897$ \\
\hline Área (km²) & $199.314,85$ & $15.418,543$ & 434,967 & 61,007 & 227,560 & 945,717 \\
\hline População (hab) & 10.686 .247 & 3.307 .945 & 1.851 .215 & 118.319 & 87.285 & 279.297 \\
\hline $\begin{array}{l}\text { Densid. } \\
\text { (hab/km²) }\end{array}$ & 53,61 & 214,54 & $4.255,99$ & $1.939,43$ & 383,57 & 295,33 \\
\hline População PR(\%) & $100,00 \%$ & $30,96 \%$ & $17,32 \%$ & $1,12 \%$ & $0,82 \%$ & $2,61 \%$ \\
\hline Água (u.a.') & 2.983 .387 & $1.000 .000^{2}$ & 654.335 & 37.815 & 22.986 & 73.822 \\
\hline Esgoto (u.a. $\left.{ }^{2}\right)$ & 1.734 .589 & $700.000^{2}$ & 575.750 & 21.053 & 14.708 & 41.606 \\
\hline
\end{tabular}

1 Unidade atendida (u.a.): imóvel ou subdivisão dotados de, no mínimo, um ponto de água identificável como unidade autônoma para efeitos de cadastro e cobrança de tarifa (SANEPAR, 2009).

2 Valor estimado.

Fonte: Adaptado de IBGE, 2010; SANEPAR, 2009

Segundo dados do Instituto Brasileiro de Geografia e Estatística (IBGE), a população da RMC passou de 907.391 (1970) para 3.307.945 habitantes (2009), concentrando 
$30,96 \%$ dos paranaenses em 6,23\% do território estadual. Desde sua criação, a RMC apresentou taxas de crescimento demográfico maiores que outras regiões metropolitanas brasileiras. $\bigcirc$ adensamento populacional superou as fronteiras de Curitiba, disseminando-se em ocupações desordenadas nos municípios de seu entorno. O impacto se concentrou em áreas ambientalmente frágeis, com restrições legais e de menor valor imobiliário (COMEC, 2006).

O aumento populacional está diretamente relacionado à demanda por ocupação urbana. Essa questão diz respeito à disponibilidade de áreas previstas pelos zoneamentos vigentes e ao cálculo da área necessária em caso de expansão, conciliando-se o uso e ocupação do solo às condicionantes físicas, bióticas e legais, bem como às condições de acessibilidade a tais áreas.

Projeções apontam que o Núcleo Urbano Central (NUC) da RMC terá um incremento populacional de 1,39 milhões de habitantes de 2000 a 2020. O maior acréscimo populacional ocorreria em São José dos Pinhais (19,99\%). A proposta de ordenamento territorial da COMEC baseia-se na otimização da urbanização de áreas menos restritivas, paralelamente à proteção de mananciais e à preservação dos biomas mais significativos. Uma das estratégias de proteção dos mananciais é o controle da ocupação das Unidades Territoriais de Planejamento (UTPs). Ao invés de proibir a ocupação, essa medida estabelece parâmetros conforme as características de cada ecossistema (COMEC, 2006).

A oferta de serviços básicos e infra-estrutura não acompanhou o ritmo da disseminação dos assentamentos populares. Embora o abastecimento de água e a coleta de lixo estejam próximos da universalização nas áreas urbanas da RMC, ainda há municípios com carências superiores a 10\% (IPARDES, 2006). Há também um descompasso entre abastecimento e tratamento das águas: em 2009, havia, em Curitiba, 654.335 unidades atendidas por abastecimento de água potável e 575.750 unidades atendidas por tratamento de águas residuárias (déficit de 12\%). A capital apresentava o balanço mais proporcional da RMC; Piraquara apresentava estatísticas da ordem de $36 \%$ e Pinhais e São José dos Pinhais, aproximadamente 44\% (SANEPAR, 2009).

O crescimento desordenado da RMC aconteceu de forma expressiva na porção a leste de Curitiba. Em São José dos Pinhais, a maior ocupação irregular localiza-se no bairro Jardim Ipê, um loteamento popular vizinho da área de estudo deste trabalho. De 1991 a 2000, o bairro Jardim Ipê apresentou o maior aumento absoluto populacional do município: 18 mil pessoas, isto é, acima de $7 \%$ a.a. Mais de $40 \%$ das famílias do Jardim Ipê ganham até dois salários mínimos mensais. Em 2005, o Jardim Alegria (situado dentro dos limites do Jardim Ipê) era a maior área de invasão do município, com 5.400 pessoas (SÃO JOSÉ DOS PINHAIS, 2005, apud TAVARES, 2005).

\section{CARACTERIZAÇÃO DA ÁREA DE ESTUDO}

A área de estudo situa-se na unidade hidrográfica do Iguaçu (coordenadas UTM 22 Sul, 7.183.100 N - 7.180.600 N e 682.000 E - 682.800 E). Confronta com a avenida 
Iraí ao norte, rodovia BR 277 ao sul, canal extravasor de água limpa a leste e rio Iraí a oeste. Pertence aos municípios de São José dos Pinhais e Piraquara e faz divisa com os municípios de Curitiba e Pinhais (Figura 1).

O clima da região, segundo a classificação de Köppen, enquadra-se como Cfb ou Clima subtropical úmido (mesotérmico), com verões brandos, geadas severas e sem estação seca. $\mathrm{O}$ mês mais quente tem temperatura média inferior a $22^{\circ} \mathrm{C}$ e, o mais frio, inferior a $18^{\circ} \mathrm{C}$ (WONS, 1982).

Assim como a maior parte da RMC, a área estudada insere-se no primeiro planalto paranaense, o qual é delimitado pela serra do Mar a leste e pela Escarpa Devoniana a oeste. A topografia é suavemente ondulada, com altitude uniforme em uma extensão de $75 \mathrm{~km}$. O perfil leste-oeste tem oscilações entre 895 e $960 \mathrm{~m}$ da serra do Mar até Curitiba. Planícies de várzea intercalam-se por sedimentos fluviais e paludais, predominando argilas plásticas pretas de húmus cru ácido e areias brancas depositadas nas várzeas do rio Iguaçu e afluentes. A base do relevo é de origem cristalina, em corte uniforme de granitos e gnaisses antigos (MAACK, 1968).

Ainda segundo Maack (1968), a baixa declividade no primeiro planalto fez com que o rio lguaçu desenvolvesse meandros de curvaturas amplas, com águas antigas e extensas várzeas. De acordo com Bittencourt et al (2000), essa configuração combinada

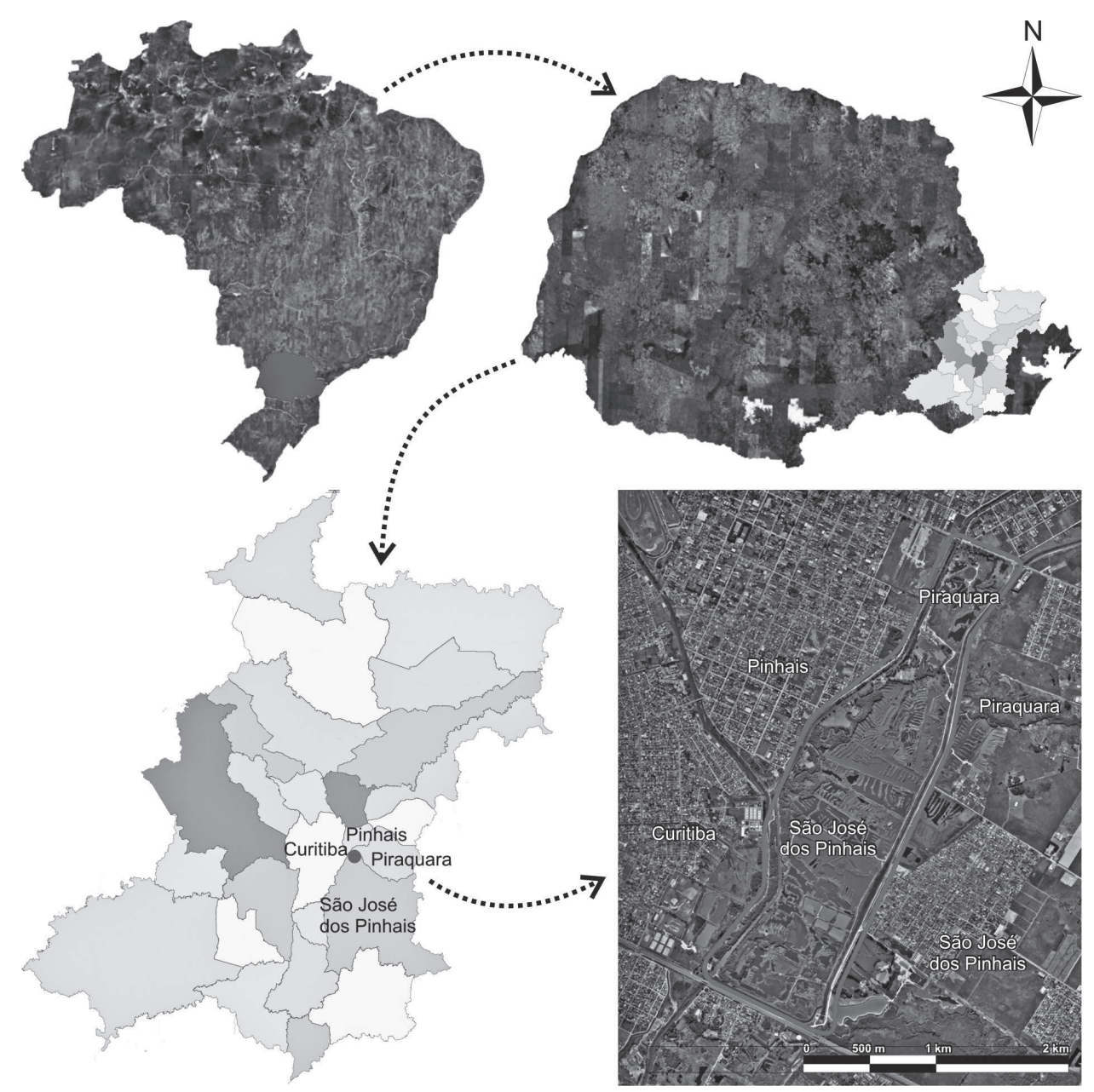

Figura 1: Brasil, Paraná, RMC e área de estudo (escala 1:50.000)

Fonte: Adaptado de Google Maps, 2009, e COMEC, 2010 
com a ocupação irregular das várzeas propicia inundações. Embora vários trechos do rio tenham sido retificados, o relevo mantém a tipologia de planície aluvional graças à construção do canal extravasor de água limpa na década de 1990. Dessa forma, a drenagem do entorno escoa para o corredor delimitado pelo rio Iraí/lguaçu e pelo canal extravasor de água limpa, viabilizando o controle estrutural de cheias e, ainda, mantendo o nível hídrico nas cavas de areia (além do lençol freático ser próximo à superfície). Essa situação é favorável à captação de água na ETA lguaçu e foi explorada na proposta de revitalização da área.

Maack (1968) complementa dizendo que a vegetação é a manifestação do clima. De acordo com a classificação climática, espera-se chuva em todos os meses do ano. Considerando a cobertura vegetal nativa, a região fitogeográfica da área estudada corresponde a campos naturais - estepes de gramíneas baixas.

A extração mineral nas várzeas do rio lguaçu redesenhou a topografia, acarretando a substituição da mata ciliar pela vegetação lacustre (FABIANOVICZ, 1998). Embora o bioma criado na área de estudo deste trabalho não corresponda à configuração original, atualmente funciona como um bolsão de amortecimento de enchentes e área remanescente de vegetação na RMC, cuja conservação configura uma forma de resistência às ocupações irregulares do entorno.

O redesenho do relevo a partir da extração de areia também alterou o arranjo florístico da área. Atualmente, pode-se dividir a gleba em dois ecossistemas (BITTENCOURT et al, 2000):

- Várzeas sujeitas à inundação periódica, com permanente teor de umidade elevado: ecossistemas preponderantes, correspondente aos remanescentes da extração de areia. Número reduzido de espécies, adaptadas às condições edáficas impostas pelo regime hídrico. Formação vegetal típica herbácea, com arbustos dispersos;

- mata ciliar do rio Iraí: ecossistema mais conservado, apesar das alterações no curso do rio. A rua Cubatão delineia a margem direita do rio Iraí a aproximados 30 metros de distância; essa área verde comporta apenas uma linha de árvores. Na margem esquerda, há uma via de servidão que dá acesso a lotes particulares. Formação vegetal tipicamente arbórea, adaptada aos fatores edáficos.

Em 1995, a área de estudo foi desapropriada pelo Decreto Estadual n. 1.468, por ser considerada imprópria para urbanização e intensificar enchentes pelo comprometimento progressivo dos padrões de escoamento superficial. Além disso, essa gleba se insere na área de implantação do PROSAM e compõe a área prevista para o Parque Metropolitano do Alto Iguaçu.

A instituição de uma UTP cria um mecanismo de ordenação de territórios partilhados por um ou mais municípios e com forte pressão por ocupação urbana (COMEC, 2006). A Lei Estadual n. 12.248/1998 determina duas classificações para a área de estudo: em Piraquara, o trecho corresponde à UTP do Guarituba (Decretos Estaduais n. 809/1999 e 6.314/2006) e em São José dos Pinhais, à UTP do Itaqui (Decreto Estadual n. 1.454/1999). Em ambas as UTPs, a área de estudo insere-se na Zona de Restrição à Ocupação. 
Com a criação da Área de Interesse Especial Regional do Iguaçu (AIERI) pelo Decreto Estadual n. 3.742/2008, a área de estudo passou a integrar o conjunto de áreas de proteção do leito do rio Iguaçu (Figura 2). A AIERI reforça a importância da proteção e recuperação das várzeas do rio lguaçu e seus afluentes.

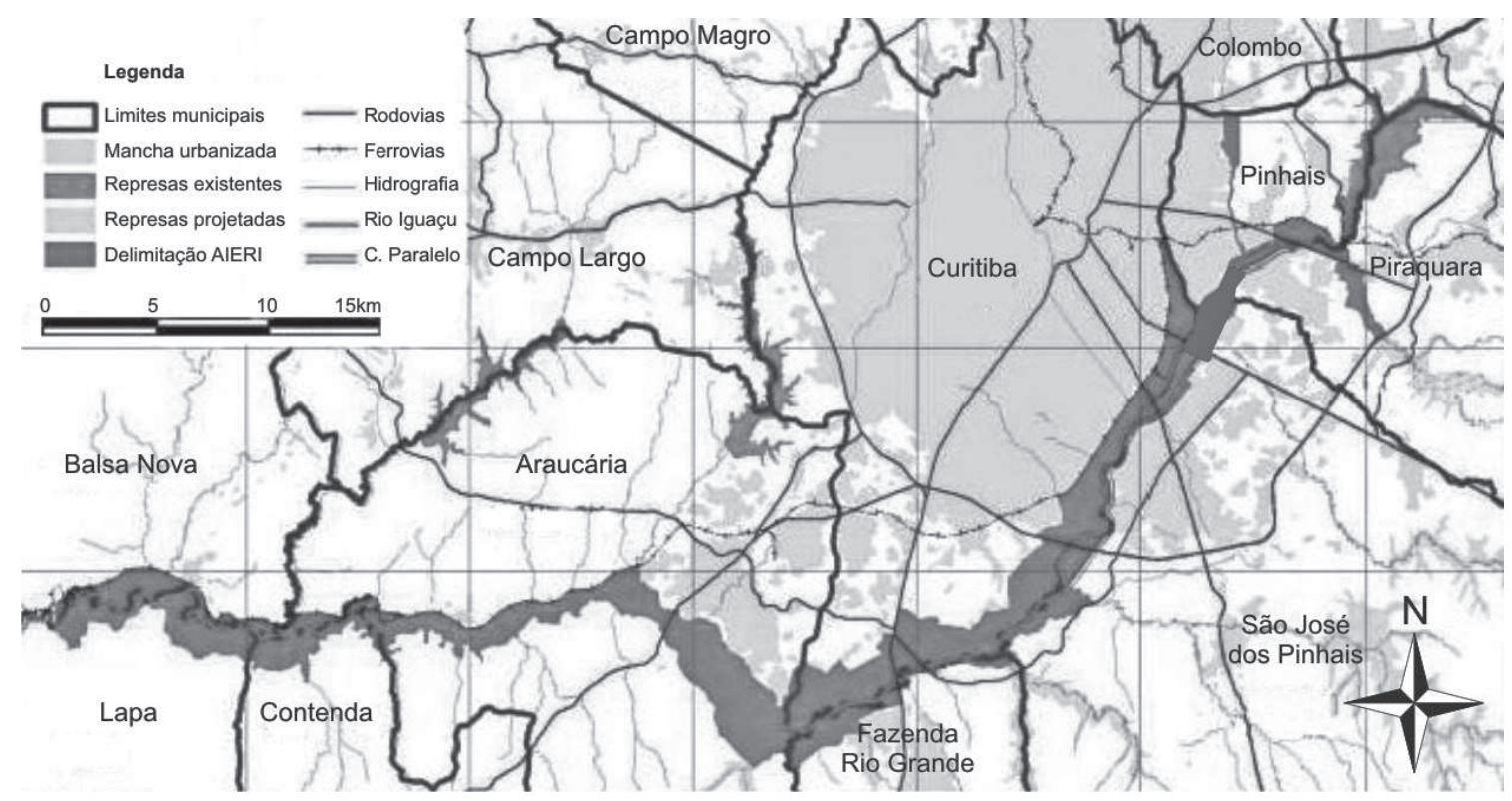

Figura 2: Área de Interesse Especial Regional do Iguaçu, área de estudo destacada em vermelho Fonte: Adaptado de PARANÁ, 2008

Em dezembro de 2009, foi firmado um Termo de Cooperação Técnica entre COMEC, ECOPARANÁ, IAP, MINEROPAR e AGUASPARANÁ. Um dos objetivos é desenvolver o Plano Diretor da AIERI em cinco anos (DIÁRIO OFICIAL DO PARANÁ, 2009). De acordo com o Decreto Estadual n. 3.742/2008, o Plano Diretor da AIERI deverá detalhar a delimitação da área. Em termos gerais, o perímetro da AIERI corresponde à cota máxima de inundação do rio lguaçu em 100 anos.

De acordo com o Decreto Estadual n 3.411/2008, a área de estudo insere-se, majoritariamente, na área de proteção da bacia do rio Palmital e um trecho próximo à BR277 faz parte da área de proteção da bacia do rio Pequeno. Do ponto de vista local, a área de estudo relaciona os seguintes ambientes: Cavas de areia, canal extravasor de água limpa e rios Iraí e Itaqui, descritos a seguir:

- Cavas de areia: parcela das cavas de areia do rio Iguaçu. Área explorada pela atividade mineradora por décadas, com maior intensidade na década de 1970 e posterior declínio na década seguinte (PEREIRA, 2007). Há mais de 65 cavas na área de estudo, cuja capacidade volumétrica média varia de $8,40 \mathrm{~m}^{3}$ a $290,70 \mathrm{~m}^{3}$ e profundidade entre 1,00 m e 4,50 m (SANEPAR, 2006);

- canal extravasor de água limpa: inicia-se próximo à captação Iraí, e segue paralelo ao rio Iguaçu até a foz do rio Miringuava. Foi construído na década de 1990 e tem como finalidade amortizar enchentes na região. Após receber os rios Itaqui e Pequeno, as águas do canal passam por baixo do leito do rio lguaçu através de um sifão, sendo dirigidas à captação Iguaçu (SUDERHSA, 2007); 
- rio Iraí: com 113 km², a sub-bacia do rio Iraí é o principal manancial da bacia do rio Iguaçu da RMC. O reservatório do Iraí supre o abastecimento público de água para mais de um milhão de pessoas da RMC. A barragem do rio Iraí apresenta riscos de eutrofização devido à baixa profundidade média $(6 \mathrm{~m})$ e tempo de detenção de 14 meses (ANDREOLI et al., 2003);

- rio Itaqui: drena os municípios de Piraquara e São José dos Pinhais, com área de 39,80 km² e vazão de 118 l/s. Recebe águas residuárias da ETAR Borda do Campo, cuja eficiência é superior a 90\%. (ANDREOLl et al, 2003). Devido à ocupação acelerada, o aumento populacional aumenta a produção de águas residuárias que, muitas vezes, são descartadas indevidamente na bacia (IAP; SEMA, 2010).

\section{ANÁLISE DA ÁGUA}

Foram realizadas nove coletas em cinco pontos (Figura 3 e Tabela 2), no período de abril de 2008 a novembro de 2009. Para avaliar o grau de interferência antrópica no ecossistema aquático foram realizadas análises dos parâmetros físicos, químicos e espectroscópicos.

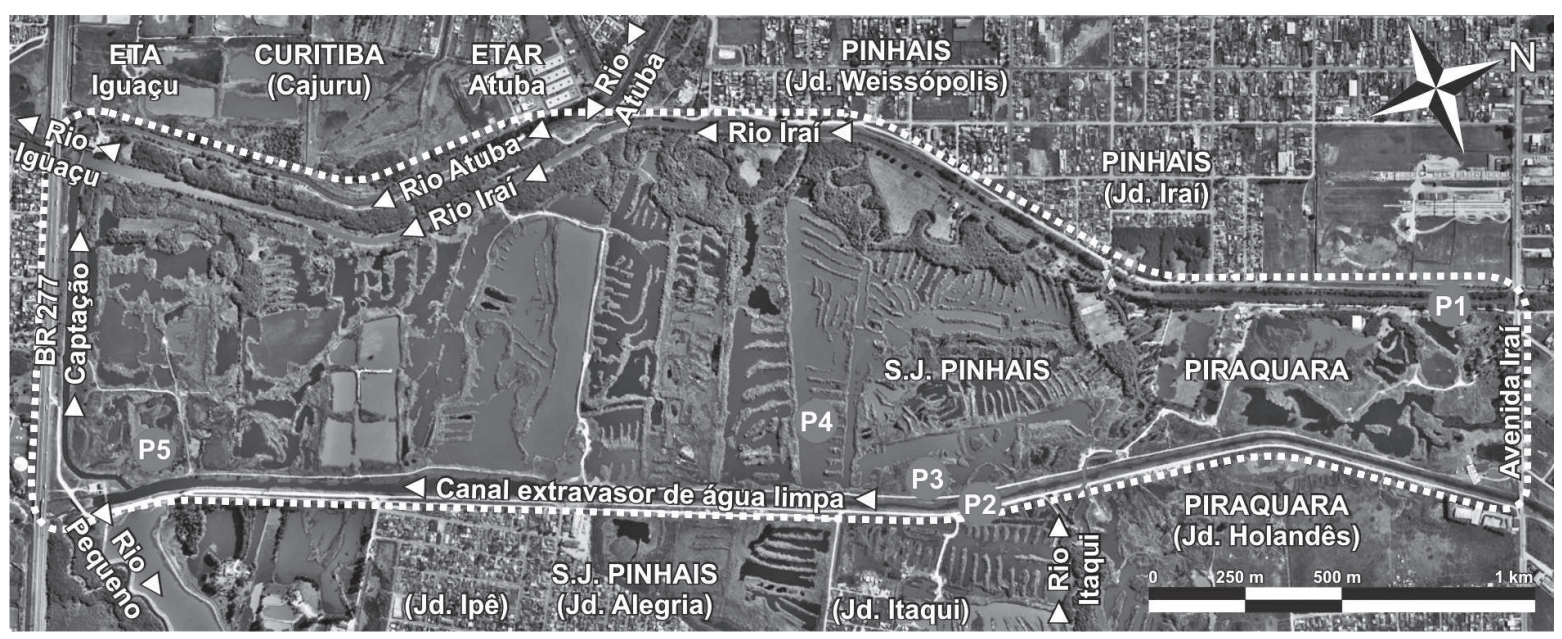

Figura 3: Localização dos pontos de coleta na área de estudo (escala 1:25.000)

Fonte: Adaptado de Google Maps, 2009

Tabela 2: Coordenadas UTM 22 Sul e localização dos pontos de amostragem

\begin{tabular}{cccc}
\hline Ponto & coordenadas UTM22 Sul & local de amostragem & altura de coleta \\
\hline P1 & $7.183 .475 \mathrm{~N} \mathrm{e} \mathrm{683.876} \mathrm{E}$ & margem direita do rio Iraí ${ }_{\perp}$ Av. Iraí) & superfície \\
\hline P2 & $7.182 .200 \mathrm{~N} \mathrm{e} \mathrm{683.823} \mathrm{E}$ & eixo do canal extravasor & superfície \\
\hline P3 & $7.182 .125 \mathrm{~N} \mathrm{e} \mathrm{683.748} \mathrm{E}$ & cava próxima ao canal extravasor & superfície \\
\hline P4 e P4 $_{F}$ & $7.181 .677 \mathrm{~N} \mathrm{e} \mathrm{683.608} \mathrm{E}$ & cava central na área de estudo & $\begin{array}{c}\text { superfície e } \\
\text { fundo }\end{array}$ \\
\hline P5 & $7.180 .082 \mathrm{~N} \mathrm{e} \mathrm{682.827} \mathrm{E}$ & cava próxima à captação de água & superfície \\
\hline
\end{tabular}

Fonte: Dados da autora, 2010 
A verificação das características limnológicas da água considerou os parâmetros para águas doces classe 2 definidos pela Resolução n. 357/2005 do Conama. Essa resolução determina que o equilíbrio ambiental e a saúde humana não devem ser afetados pela deterioração antrópica dos recursos hídricos. Cabe reforçar que as águas doces classe 2 podem ser destinadas:

a) Ao abastecimento para consumo humano, após tratamento convencional;

b) à proteção das comunidades aquáticas;

c) à recreação de contato primário, tais como natação, esqui aquático e mergulho, conforme a Resolução n. 274/2000 do Conama;

d) à irrigação de hortaliças, plantas frutíferas e de parques, jardins, campos de esporte e lazer, com os quais o público possa vir a ter contato direto; e

e) à aquicultura e à atividade de pesca (CONAMA, 2005).

$\bigcirc$ enquadramento dos corpos de água é um instrumento de planejamento ambiental, não uma mera classificação. A definição de parâmetros não se baseia no estado atual, mas na qualidade ideal à necessidade coletiva. Em linhas gerais, a água armazenada nas cavas da área de estudo atendeu aos requisitos de enquadramento em classe 2; já a água do rio Iraí infringiu alguns parâmetros, conforme consta na Tabela 3.

Tabela 3: Comparação de alguns parâmetros para águas doces classe 2: segundo Resolução n. 357/2005 do Conama e dados amostrados nos pontos P1 (rio Iraí) e P4 (cava)

\begin{tabular}{lccccc}
\hline \multirow{2}{*}{$\begin{array}{c}\text { Parâmetro } \\
\text { (unidade) }\end{array}$} & CONAMA & \multicolumn{2}{c}{$\mathrm{Pl}$} & \multicolumn{2}{c}{$\mathrm{P}_{\mathrm{s}}$} \\
\cline { 3 - 6 } & & média & desvio padrão & média & desvio padrão \\
\hline E. coli (coli/L) & $\leq 10.000$ & 9.617 .500 & 12.908 .572 & 2.893 & 3.441 \\
\hline $\mathrm{DBO}_{5}(\mathrm{mg} / \mathrm{L})$ & $\leq 5$ & 20,63 & 17,53 & 2,03 & 0,05 \\
\hline $\mathrm{OD}(\mathrm{mg} / \mathrm{L})$ & $\geq 5$ & 3,28 & 2,14 & 8,24 & 1,48 \\
\hline $\mathrm{pH}(-)$ & 6,0 a 9,0 & 6,79 & 0,31 & 6,85 & 1,13 \\
\hline P-total $(\mathrm{mg} / \mathrm{L})$ & $\leq 0,03^{1}$ & - & - & 0,034 & 0,040 \\
\hline P-total $(\mathrm{mg} / \mathrm{L})$ & $\leq 0,1^{2}$ & 0,448 & 0,320 & - & - \\
\hline $\mathrm{N}$-nitrito $(\mathrm{mg} / \mathrm{L})$ & $\leq 1,0$ & 0,050 & 0,037 & 0,003 & 0,003 \\
\hline $\mathrm{N}$-nitrato $(\mathrm{mg} / \mathrm{L})$ & $\leq 10,0$ & 0,541 & 0,727 & 0,035 & 0,059 \\
\hline Sulfato $(\mathrm{mg} / \mathrm{L})$ & $\leq 250$ & 40,60 & 49,32 & 8,76 & 10,83 \\
\hline
\end{tabular}

' Esse índice se refere a ambientes lênticos; por isso, não foi adotado em P1

2 Esse índice se refere a ambientes lóticos; por isso, não foi adotado em P4

Fonte: Adaptado de Conama, 2005; dados da autora, 2010

Embora a área de estudo situe-se em uma região de ocupações irregulares, a água armazenada nas cavas de areia atualmente encontra-se pouco degradada pela ação antrópica do entorno. Essa situação favorável das cavas deve-se à ação estanque do rio Iraí e do canal extravasor de água limpa, que funcionam como uma barreira à contaminação das cavas por águas residuárias domésticas. Esses cursos de água, em 
compensação, tiveram suas características físicas e químicas alteradas pelo aporte de águas residuárias e polvição difusa, fenômenos relacionados à urbanização. Enquanto - Carbono Orgânico Dissolvido (COD) encontrado nas cavas foi de origem autóctone (natural do ambiente aquático), o COD encontrado no rio Iraí e no canal extravasor de água limpa tem forte influência antrópica, além de certa influência pedogênica.

\section{DIRETRIZES DE REVITALIZAÇÃO DA ÁREA DE ESTUDO}

Dada a relevância do rio Iguaçu no contexto paranaense e a inserção de sua nascente na área estudada neste trabalho, a importância da recuperação dessa área é inegável. Uma gestão ambiental adequada deve conciliar benefícios à natureza e à população, assegurando a conservação ambiental e o bem-estar social. Para que essa gestão se concretize, pressupõe-se o reconhecimento de um território comum, com ações integradas e independentes de limites políticos.

Embora Curitiba vivencie boas práticas de planejamento urbano, os demais municípios que integram a RMC expandiram-se de forma desordenada. Em 1995 a COMEC iniciou uma política de intervenções estatais na região, com destaque para o recente processo de industrialização. Outra mudança estrutural foi a consolidação do reservatório do rio Iraí, que favoreceu a implantação de chácaras de recreação em substituição às propriedades agrícolas. Esse fato exemplifica a valorização de uma área pela mudança de vocação econômica e social (BITTENCOURT et al, 2000). No caso da área de estudo, propõe-se a substituição da extração de areia pela recuperação ambiental; assim, a área manterá o caráter de planície aluvional e passará a exercer também a função de entretenimento.

Termo de Cooperação Técnica da AIERI é um canal de comunicação entre diversos órgãos que facilita a abordagem multidisciplinar. Após a conclusão do plano diretor, sugere-se o prosseguimento do Termo visando ao desenvolvimento de propostas pontuais de revitalização como, por exemplo, na área de estudo deste trabalho.

No que concerne à gestão participativa, as diretrizes de revitalização da área propiciam a inserção de diversos setores da comunidade. Um dos focos da proposta foi a disseminação da educação ambiental, que formaliza a interface entre meio acadêmico e usuários. A sensibilização da população local será fundamental para a concretização da proposta, pois cria um senso de responsabilidade pelo uso correto do ambiente e combate ações de vandalismo.

A concepção da maioria dos parques de Curitiba e RMC teve como foco a importância das áreas verdes; os corpos de água tinham como finalidade apenas a contenção de cheias. A água não pode ser tratada como um elemento secundário, mas sim como principal objeto da proteção ambiental. Além disso, a água é peculiar: sua interação com o meio é intensa e de alto alcance; seu comportamento é expansivo (nem toda barreira para o homem ou animais é eficiente para a água).

A revitalização da área de estudo presumiu uma abordagem interdisciplinar que considerasse a atuação de múltiplos condicionantes (hidrológico, geológico, biológico, 
econômico, social, etc.). As cavas de areia oferecem uma oportunidade única de apropriação paisagística, pois a intervenção antrópica pode ser revertida na adaptação da natureza a um novo ecossistema.

O partido da concepção paisagística baseou-se na predominância de áreas alagadas e na exploração de seu potencial decorativo, recreativo e utilitário. As escassas áreas transitáveis foram definidas como áreas de permanência e eixos de circulação, complementados por aterros e estruturas suspensas sobre as áreas alagadas. Para viabilizar o desenvolvimento físico-territorial, a gleba foi dividida em setores principais, descritos a seguir e representados na Figura 4:

1 - Extração mineral controlada: área vizinha ao ponto de amostragem P1. No trecho pertencente ao município de Piraquara, ainda há reservas de areia. Devido à grande demanda por esse recurso no âmbito da construção civil na RMC foi admitida a extração mineral, desde que respeitada a regulamentação relacionada. Propõe-se uma parceria com setor privado: em troca do aval da extração, as mineradoras serão responsabilizadas pela readequação do desenho das cavas já exauridas, bem como das próprias cavas de onde extraíram areia. Quando a área estiver esgotada, propõe-se o estudo de uma área de recreação pública voltada à comunidade de Pinhais e Piraquara.

2 - Área de amortecimento: visa conter a água da drenagem de regiões limítrofes, além de proteger a integridade do complexo de wetlands construídas em períodos de chuva intensa. A área de amortecimento dificulta o transbordo das wetlands, evitando a contaminação acidental do meio ambiente e também o escape de plantas flutuantes. Pressupõe manejo adequado.

3 - Área de recreação pública: propõe-se a implantação de uma área de lazer voltada à população local, conectada ao Jardim Ipê por uma ponte peatonal de madeira sobre o canal extravasor de água limpa. A proposta de lagoas de pesca aproveita a conformação regular de um conjunto de cavas, cujo desenho se originou de um loteamento parcialmente implantado. Propõe-se um circuito de caminhada entre as lagoas e um deck para pescaria.

4 - Centro de Pesquisa e Educação Ambiental: próximo ao ponto de amostragem P5. Esse é o local mais próximo da principal via de acesso à área de estudo (BR 277), e apresenta eixos de circulação predefinidos. Na intersecção dos eixos, propõe-se a construção de um centro de pesquisa e educação ambiental voltado a pesquisadores da UTFPR, responsáveis pelo monitoramento da área de estudo e à visitação de público externo. É prevista uma área de estacionamento próxima à BR 277 e também um mirante de uso compartilhado com a Polícia Ambiental Força Verde.

5 - Manutenção e recuperação da mata ciliar: inclui o ponto de amostragem P1. Propõe-se a recuperação da mata ciliar do rio Iraí por meio do plantio de espécies nativas, especialmente árvores. Além da área de várzea, propõe-se a manutenção dos remanescentes florestais do restante da gleba e o adensamento vegetal nas áreas de amortecimento.

6 - Complexo de wetlands construídas: inclui os pontos de amostragem P3 e P4. Setor preponderante. Propõe-se o uso das áreas alagadas como alternativa de sa- 
neamento menos agressivo ao meio ambiente. Ao desviar parcialmente $\circ$ rio Iraí para esse conjunto de cavas, a água é submetida a métodos naturais de depuração. Salienta-se a necessidade de manejo, isolamento e monitoramento do sistema, para evitar a contaminação do meio ambiente e a eutrofização da área. São previstas duas opções de deságue, conforme o grau de tratamento atingido:

a) Retorno ao rio Iraí à montante da foz do rio Atuba: a água tratada retorna ao leito do rio Iraí. Nessa alternativa, as wetlands proporcionam um tratamento prévio à parte da água do rio Iraí, retendo nutrientes e facilitando o tratamento global das águas;

b) deságue na captação do canal extravasor de água limpa: com o monitoramento rigoroso da água, o produto final do tratamento das wetlands pode ser aplicado no abastecimento público em situações de estiagem, desde que se enquadre na classe 2 da Resolução n. 357/2005 do Conama. Um sistema de comportas bloqueia temporariamente o retorno ao rio Iraí e direciona a água para a captação do canal extravasor de água limpa, que segue então para a ETA Iguaçu.

Uma wetland é uma área frequentemente inundada por água subterrânea ou superficial, com predomínio de fauna e flora adaptadas a solos saturados. O sistema apresenta múltiplas funções: hábitat, fonte de alimento, melhoria natural da qualidade da água, participação no ciclo hidrológico, contenção de cheias, espaço de lazer, educação, pesquisa e apreciação da paisagem, dentre outros (EPA, 2010).

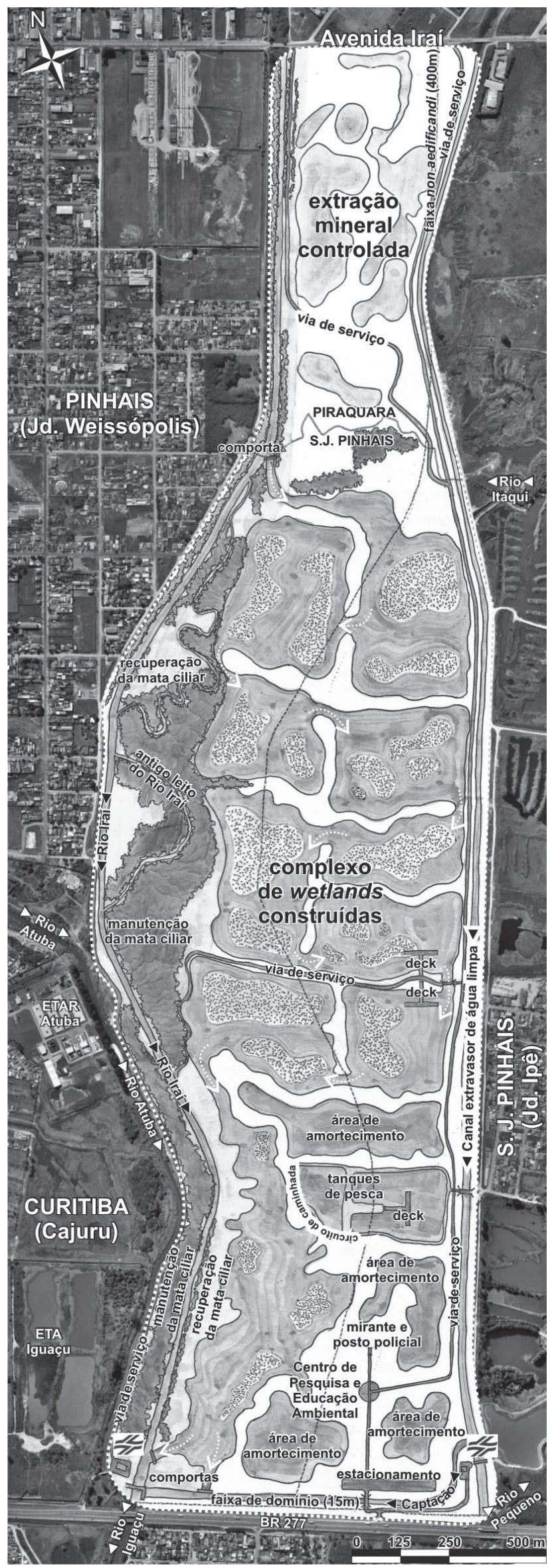

Figura 4: Plano massa de revitalização da área estudada (1:20000)

Fonte: Adaptado de Google Maps, 2010 
Graças ao baixo custo de manutenção e à alta capacidade de remoção de polventes, a wetland tem sido introduzida de maneira artificial como mecanismo de tratamento hídrico. No entanto, a magnitude da área demandada e o investimento em movimentação de terra podem inviabilizar a implantação de uma wetland construída (LAUTENSCHLAGER, 2001). No caso da área de estudo, extração de areia, indiretamente, estabeleceu uma configuração primária favorável, dispensando grandes alterações de topografia.

\section{CONCLUSÃO}

A área de estudo deste trabalho é uma retrato da dificuldade de gestão de espaços públicos no Brasil. A diversidade de atores envolvidos (comunidade do entorno, órgãos da administração pública, iniciativa privada na extração mineral, dentre outros) somada à localização em quádrupla fronteira desafiam a conciliação de múltiplos interesses. $\bigcirc$ resultado é uma situação de indefinição pela dificuldade de concretização de objetivos comuns. Um espaço que deveria ser para todos acaba sendo uma terra de ninguém.

No caso da gestão dos recursos hídricos, a falta de comprometimento da sociedade e a fiscalização insuficiente dão margem ao mau uso desse bem coletivo. Uma infinidade de agressões ambientais pode ser verificada na área de estudo ao longo do desenvolvimento deste trabalho; mesmo assim, a água armazenada nas cavas de areia ainda apresenta parâmetros satisfatórios de caracterização. Quanto mais cedo ocorrer a revitalização da área, mais simples e viável será o processo de recuperação do ecossistema.

Apesar da histórica preocupação de Curitiba com o meio ambiente e da recente eleição da capital paranaense como a cidade mais sustentável do mundo, a questão das áreas verdes na RMC ainda é bastante deficiente. A proposta de revitalização da área estudada estende à RMC a consciência ambiental curitibana, iniciativa ainda mais relevante por envolver a questão dos recursos hídricos. Destaca-se também a localização estratégica na rota de acesso do Aeroporto Internacional Afonso Pena, que favorece a divulgação da proposta.

A área de estudo deste trabalho é apenas um recorte da várzea do rio Iguaçu na RMC; ao longo do rio há mais de 30 áreas de cavas de areia que prescindem de projetos de revitalização. A proposta deste trabalho é um projeto-piloto que pode ser perpetuado em áreas de configuração semelhante.

O adensamento populacional é tão elevado na RMC que a sub-bacia do Alto Iguaçu é a única no Paraná a apresentar densidade demográfica superior a 100 hab./ $\mathrm{km}^{2}$. Esse valor é decorrente das elevadas taxas de crescimento populacional, e, dos oito municípios paranaenses com maior demanda de água por dia, três se situam na RMC (Curitiba, Colombo e São José dos Pinhais). Da mesma forma, a quantidade de águas residuárias lançadas por esses municípios na bacia hidrográfica do Alto Iguaçu é um reflexo dessa demanda por recursos hídricos. $\bigcirc$ emprego de wetlands na proposta de revitalização é uma forma de amenizar o impacto da atividade antrópica no entorno da área de estudo e, ocasionalmente, proporcionar uma fonte alternativa de 
abastecimento hídrico (desde que a água tratada se enquadre na classe 2 da Resolução n. 357/2005 do Conama).

Embora a degradação ambiental seja fruto da atividade antrópica, o estímulo ao uso consciente do espaço é a melhor forma de preservá-lo. A proibição generalizada incita o comportamento displicente, ao passo que o uso regulamentado promove o senso coletivo de responsabilidade em relação ao espaço público. $\bigcirc$ envolvimento da comunidade local é essencial ao uso adequado do espaço proposto na área de estudo.

\section{Bibliografia}

ANDREOLI, Cleverson Vitório; DALARMI, Osvaldo; LARA, Aderlene Inês; RODRIGUES, Eloize Motter; ANDREOLI, Fabiana de Nadai. Os mananciais de abastecimento do sistema integrado da região metropolitana de Curitiba - RMC. SANARE - Revista Técnica da Sanepar, Curitiba, v. 12, n. 12, 1999.

ANDREOLI, Cleverson Vitório. Mananciais de abastecimento: planejamento e gestão. Estudo de caso do Altíssimo Iguaçu. In: JACOBS, Gerson Antonio; RIZZI, Nivaldo Eduardo (Orgs.). O uso dos mananciais da RM Curitiba - a ocupação do espaço físico da bacia do Altíssimo Iguaçu. Curitiba: Sanepar; Finep, 2003.

BRASIL. Lei Complementar n. 14, de 08 de junho de 1973. Estabelece as regiões metropolitanas de São Paulo, Belo Horizonte, Porto Alegre, Recife, Salvador, Curitiba, Belém e Fortaleza. Diário Oficial da República Federativa do Brasil, Poder Executivo, Brasília, DF, 11 jun.1973. Disponível em: http://legislação.planalto.gov.br. Acesso em: 25 abr. 2010.

BITTENCOURT, Alexander; BONIERSKI, Elise do Carmo; HAYAKAWA, luri Fukuda; SILVA, Walter da. Parque das diversidades ambientais do Umbará: uma proposta de manejo ecológico. Monografia de Especialização - Programa de Pós-Graduação em Gestão e Engenharia Ambiental, Universidade Federal do Paraná, Paraná, 2000.

COMEC. COORDENAÇÃO DA REGIÃO METROPOLITANA DE CURITIBA. Plano de Desenvolvimento Integrado da Região Metropolitana de Curitiba: propostas de ordenamento territorial e novo arranjo institucional. Curitiba: COMEC, 2006.

. Disponível em: <http://www.comec.pr.gov.br> Acesso em: 01. maio 2010.

CONAMA. CONSELHO NACIONAL DO MEIO AMBIENTE. Resolução n. 357, de 17 de março de 2005. Dispõe sobre classificação dos corpos de água e diretrizes ambientais para seu enquadramento, bem como estabelece as condições e padrões de lançamento de efluentes, e dá outras providências. Diário Oficial da República Federativa do Brasil, Brasília, DF, 18. mar. 2005. Disponível em: <http://www.mma.gov.br/conama/> Acesso em: 15. nov. 2009.

EPA. US ENVIRONMENTAL PROTECTION AGENCY. Design manual: constructed wetlands and aquatic plant systems for municipal wastewater treatment. Cincinnati: Center for Environmental Research Information, 1998.

FABIANOVICZ, Rosemari. Conflitos entre a extração de areia e a expansão urbana na região da Grande Curitiba (PR). 1998. Dissertação (Mestrado) - Instituto de Geociências, Universidade Estadual de Campinas, Campinas, 1998.

GOOGLE MAPS. Disponível em: <http://maps.google.com.br> Acesso em: 14. nov. 2009.

IAP. INSTITUTO AMBIENTAL DO PARANÁ; SEMA - SECRETARIA DE ESTADO DE MEIO AMBIENTE E RECURSOS HÍDRICOS. Relatório de qualidade das águas: reservatórios do estado do Paraná, 2005 a 2008, e rios da bacia do Alto Iguaçu, na região metropolitana de Curitiba, 2005 a 2009. In: DIA MUNDIAL DA ÁGUA: ÁGUA LIMPA PARA UM MUNDO SAUDÁVEL, 2010, Curitiba. Anais... Curitiba: IAP, 2010. 1 CD-ROM.

IBGE. INSTITUTO BRASILEIRO DE GEOGRAFIA E ESTATÍSTICA. Disponível em: http://www.ibge.gov.br. Acesso em: 27. abr. 2010.

IPARDES. INSTITUTO PARANAENSE DE DESENVOLVIMENTO ECONÔMICO E SOCIAL. Referências ambientais e socioeconômicas para o uso do território do Estado do Paraná: uma contribuição ao zoneamento ecológico-econômico - ZEE. Curitiba: IPARDES, 2006.

LAUTENSCHLAGER, Sandro Rogério. Modelagem do desempenho de wetlands construídas. 2001. Dissertação (Mestrado) - Departamento de Engenharia Hidráulica e Sanitária, Escola Politécnica, Universidade de São Paulo, São Paulo, 2001.

MAACK, Reinhard. Geografia física do Estado do Paraná. Curitiba: Max Roesner, 1968. 
PARANÁ. Decreto n. 1.468, de 15 de dezembro de 1995. Declara de utilidade pública, para fins de desapropriações, parciais ou totais, os terrenos e benfeitorias situados nas áreas abaixo descritas. Diário Oficial do Estado do Paraná, Curitiba, 15 dez. 1995. Disponível em: http://www.legislação.pr.gov.br. Acesso: 05 jan. 2011.

. Lei n. 12.248, de 31 de julho de 1998. Cria o Sistema Integrado de Gestão e Proteção de Mananciais da RMC. Diário Oficial do Estado do Paraná, Curitiba, 03 ago. 1998. Disponível em: http://www.legislação.pr.gov. br. Acesso em: 25. abr. 2010.

Decreto n. 809, de 31 de maio de 1999. Declara para os fins de que trata a Lei Especial de Proteção dos Mananciais da RMC. Diário Oficial do Estado do Paraná, Curitiba, 01 jun. 1999. Disponível em: http://www. legislação.pr.gov.br. Acesso em: 01 maio 2010.

Decreto n. 1.454, de 26 de outubro de 1999. Declara para os fins de que trata o inciso da Lei Especial de Proteção dos Mananciais da RMC, como Unidade Territorial de Planejamento. Diário Oficial do Estado do Paraná, Curitiba, 27. out. 1999. Disponível em: <http://www.legislação.pr.gov.br> Acesso em: 01 maio 2010.

Decreto n. 6.314, de 29 de março de 2006. Dispõe sobre o Decreto Estadual n. 809, de 31 de maio de 1999. Diário Oficial do Estado do Paraná, Curitiba, 29 mar. 2006. Disponível em: http://www.legislação.pr.gov. br. Acesso em: 01 maio 2010.

Decreto n. 3.411 , de 10 de setembro de 2008. Declara as áreas de interesse de mananciais de abastecimento público da região metropolitana de Curitiba e dá outras providências. Diário Oficial do Estado do Paraná, Curitiba, 11. set. 2008. Disponível em: <http://www.legislação.pr.gov.br> Acesso em: 16 set. 2010.

Decreto n. 3.742, de 12 de novembro de 2008. Declara a área de interesse especial regional do lguaçu na região metropolitana de Curitiba e dá outras providências. Diário Oficial do Estado do Paraná, Curitiba, 12. nov. 2008. Disponível em: http://www.legislação.pr.gov.br. Acesso em: 05 jan. 2011.

Termo de Cooperação Técnica n. 02/2009 - COMEC/ECOPARANÁ/IAP/MINEROPAR/SUDERHSA. Diário Oficial do Estado do Paraná, Curitiba, 22 dez. 2009. Disponível em: http://www.legislação.pr.gov.br. Acesso em: 01 . maio 2010.

PEREIRA, Christian de Assis. Estudo de caso: utilização das águas das cavas da várzea do rio lguaçu para abastecimento de água da região metropolitana de Curitiba. 2007. Trabalho de Diplomação - Departamento de Química e Biologia, Universidade Tecnológica Federal do Paraná, Paraná, 2007.

SANEPAR. Companhia da Saneamento do Paraná. Projeto de interligação das cavas de areia do rio lguaçu. Curitiba: SANEPAR, 2006. $1 \mathrm{mapa}$, colorido, $841 \times 1.189 \mathrm{~cm}$.

Disponível em: http://www.sanepar.com.br. Acesso em: 05. dez. 2009.

SETTI, Arnaldo Augusto; LIMA, Jorge Enoch Furquim Werneck; CHAVES, Adriana Goretti de Miranda; PEREIRA, Isabella de Castro. Introdução ao gerenciamento de recursos hídricos. Brasília: Agência Nacional de Energia Elétrica, Superintendência de Estudos e Informações Hidrológicas, 2000.

SUDERHSA. SUPERINTENDÊNCIA DE DESENVOLVIMENTO DE RECURSOS HÍDRICOS E SANEAMENTO AMBIENTAL. Relatório de diagnóstico: Plano da bacia do Alto Iguaçu e afluentes do rio Ribeira. Curitiba: SUDERHSA, 2007.

TAVARES, Lilian Pérsia de Oliveira. São José dos Pinhais no contexto da recente industrialização metropolitana: reflexos socioespaciais. Revista Paranaense de Desenvolvimento, Curitiba, n. 108, p. 33-59, 2005.

WHO. WORLD HEALTH ORGANIZATION. World Health Statistics 2008. Genebra: WHO, 2008.

WONS, laroslaw. Geografia do Paraná. Curitiba: Ensino Renovado, 1982. 